\title{
Monoaminergic modulation of photoreception in ascidian: evidence for a proto-hypothalamo- retinal territory
}

\author{
Florian Razy-Krajka ${ }^{1,7}$, Euan R Brown ${ }^{2,8}$, Takeo Horie ${ }^{3,4,5,6}$, Jacques Callebert ${ }^{4}$, Yasunori Sasakura ${ }^{3}$, \\ Jean-Stéphane Joly ${ }^{1}$, Takehiro G Kusakabe ${ }^{5}$ and Philippe Vernier ${ }^{1 *}$
}

\begin{abstract}
Background: The retina of craniates/vertebrates has been proposed to derive from a photoreceptor prosencephalic territory in ancestral chordates, but the evolutionary origin of the different cell types making the retina is disputed. Except for photoreceptors, the existence of homologs of retinal cells remains uncertain outside vertebrates.

Methods: The expression of genes expressed in the sensory vesicle of the ascidian Ciona intestinalis including those encoding components of the monoaminergic neurotransmission systems, was analyzed by in situ hybridization or in vivo transfection of the corresponding regulatory elements driving fluorescent reporters. Modulation of photic responses by monoamines was studied by electrophysiology combined with pharmacological treatments.

Results: We show that many molecular characteristics of dopamine-synthesizing cells located in the vicinity of photoreceptors in the sensory vesicle of the ascidian Ciona intestinalis are similar to those of amacrine dopamine cells of the vertebrate retina. The ascidian dopamine cells share with vertebrate amacrine cells the expression of the keytranscription factor Ptf1a, as well as that of dopamine-synthesizing enzymes. Surprisingly, the ascidian dopamine cells accumulate serotonin via a functional serotonin transporter, as some amacrine cells also do. Moreover, dopamine cells located in the vicinity of the photoreceptors modulate the light-off induced swimming behavior of ascidian larvae by acting on alpha2-like receptors, instead of dopamine receptors, supporting a role in the modulation of the photic response. These cells are located in a territory of the ascidian sensory vesicle expressing genes found both in the retina and the hypothalamus of vertebrates (six3/6, Rx, meis, pax6, visual cycle proteins).
\end{abstract}

Conclusion: We propose that the dopamine cells of the ascidian larva derive from an ancestral multifunctional cell population located in the periventricular, photoreceptive field of the anterior neural tube of chordates, which also gives rise to both anterior hypothalamus and the retina in craniates/vertebrates. It also shows that the existence of multiple cell types associated with photic responses predates the formation of the vertebrate retina.

\section{Background}

The vertebrate retina is made of multiple cell types, including photoreceptors, bipolar, amacrine, horizontal and ganglion cells and glia [1]. Although photoreceptors are widespread in animals, the other retinal cell types have no obvious counterparts in non-vertebrate species,

\footnotetext{
* Correspondence: vernier@inaf.cnrs-gif.fr

'Neurobiology and Development, UPR3294, Institut de Neurobiologie Alfred Fessard, Centre National de la Recherche Scientifique, Gif-sur-Yvette, 91190, France

Full list of author information is available at the end of the article
}

and as a result, the question of their evolutionary origin is left uncertain [2-4]. Based on molecular fingerprints (mostly the expression of transcription factors and components of the phototransduction machinery), two categories of photoreceptor cells (PRCs), ciliary and rhabdomeric PRCs, once thought to be respectively specific to vertebrates and protostomes, were proposed to be sister cell types instead, and co-exist in most bilaterian species [5]. In addition, strong evidence supports the view that ganglion cells of the vertebrate retina could be
C Biomed Central

(c) 2012 Razy-Krajka et al; licensee BioMed Central Ltd. This is an Open Access article distributed under the terms of the Creative Commons Attribution License (http://creativecommons.org/licenses/by/2.0), which permits unrestricted use, distribution, and reproduction in any medium, provided the original work is properly cited. 
derived from ancestral rhabdomeric PRCs, whereas rods and cone PRCs may originate from ancestral ciliary PRCs [2-4]. Thus, rods, cones and ganglion cells would be the earliest cellular components of the retina of ancient craniates (craniates include vertebrates plus the hagfishes, a group of marine species which may lack true vertebra but have most characters in common with vertebrates [6,7]). Supporting this contention, the adult hagfish retina is only made of rods and cones connected to ganglion cells $[8,9]$. Since the retina of lampreys (proposed to be the sister group of hagfish within the cyclostomes [10]) exhibits the whole complement of vertebrate retinal cell types [11], the diversification of retinal cell types should have occurred after the divergence of the hagfish ancestor from other jawless vertebrates, contradicting the proposed monophyly of cyclostomes. The alternative hypothesis would be that the multiple retinal cell types were generated before the emergence of craniates from ancestral chordates and that the hagfishes, which live in the dark, have secondarily lost several of the retinal cell types. Indeed, other work recently suggested that the bipolar cells of the vertebrate retina could be evolutionarily related to the transmedullary neurons of the eye of Drosophila and other protostomes, whereas vertebrate ganglion cells may be homologous to the projection neurons of the lobula complex of Drosophila and other insects [4]. This hypothesis sets the diversification of retinal cell types much earlier in bilaterian evolution. Overall, the question of the origin of the different cell types of the vertebrate retina would benefit from studies in species having diverged closer to the emergence of craniates/vertebrates.

In this respect, the ascidian tunicates, such as Ciona intestinalis, are of interest since they belong to the sister group of craniates $[12,13]$, and their larval central nervous system shares a regionalization pattern with vertebrate brains $[14,15]$. Three distinct groups of PRCs have been depicted within the sensory vesicle of the ascidian larva [16]. Two of the ascidian PRC groups are associated with the pigmented ocellus, while the third one corresponds to a non-pigmented ocellus. However, the question of the existence of homologues of retinal cell types of vertebrates other than PRCs in the sensory vesicle of ascidians had not been addressed so far.

In particular, amacrine cells of the vertebrate retina make a class of auxiliary cells expressing various neurotransmitters, such as GABA, glycine, serotonin (5-HT), but also dopamine (DA) [1]. They are conserved among craniates [17], except hagfish [8]. In ascidians, a single group of dopamine-synthesizing cells exists, which is located on the left side of the postero-ventral wall of the sensory vesicle, adjacent to the third group of photoreceptors [18]. We investigated here whether they could share similarities with dopamine amacrine cells of the vertebrate retina. We found that many molecular and functional characteristics of amacrine cells are also present in the DA cells of the ascidian sensory vesicle, rendering plausible the idea that the two cell types share a common evolutionary origin.

\section{Results}

Similarities between dopamine cells of the sensory vesicle of Ciona and amacrine cells of the vertebrate retina

The single population of dopamine-synthesizing cells in the sensory vesicle of Ciona intestinalis was previously described to co-express the transcription factor-encoding genes CiMeis and CiSix3/6 with transcripts encoding tyrosine hydroxylase, the limiting enzyme of catecholamine biosynthesis $(\mathrm{CiTH})$ [18]. Since the vertebrate hypothalamus also comprises several populations of DAsynthesizing cells, this finding was taken as evidence for the presence of the $\mathrm{CiTH}$-positive cells in a protohypothalamic domain [19]. However, since the vertebrate counterparts of CiMeis and CiSix3/6 are both found in the retina [20-22], and since the DA cells of the sensory vesicle of ascidian larvae are located close to photoreceptors, we wanted to test the hypothesis that they may also be homologous to vertebrate amacrine cells.

Based on the expression pattern of transcription factors accessible in the Ciona ghost database http://ghost. zool.kyoto-u.ac.jp[23] and the Aniseed database http:// aniseed-ibdm.univ-mrs.fr[24], we identified CiPtf1a as a gene of particular interest, as its vertebrate homologue is specifically expressed in amacrine cells, many of which synthesize DA in addition to GABA $[25,26]$. Identification of the CiPtf1a transcript by in situ hybridization at larval stage suggested it was localized in the same cells as $T H$, which was confirmed by the coexpression of fluorescent reporters driven by the promoters of genes encoding CiTH (pCiTH-CFP) and CiPtfla (CiPtf1a-Kaede) (Figure 1a-c). The TH-Ptf1A co-expression brings a significant evidence of the similarities that exist between DA cells of the ascidian sensory vesicle and amacrine cells of the vertebrate retina.

To further substantiate the phenotype of these dopaminergic cells [18], we identified the whole complement of genes coding for monoaminergic markers in the published genomes of Ciona intestinalis [27] and Ciona savignyi [28] by comparison with vertebrate sequences (see list in Additional file 1, Table I). As analyzed by in situ hybridization in late tail-bud embryos, monoaminergic markers were located in two regions: (i) the ventral part of the posterior sensory vesicle corresponding to the CiTH population previously described [18], and (ii) a bilateral cell cluster located posteriorly, outside the sensory vesicle, as revealed by the CiNut hybridization signal, a pan-neuronal marker (Figure 2a-j). The second cluster probably corresponds to cells expressing 


\section{pCiTH-CFP}

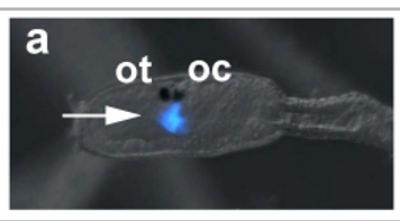

CiPtf1a-Kaede

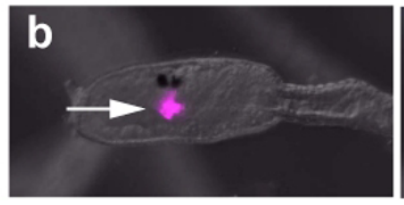

merged

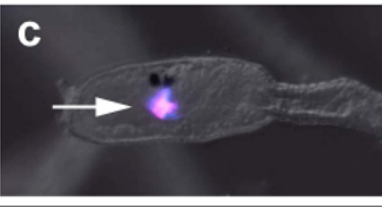

d

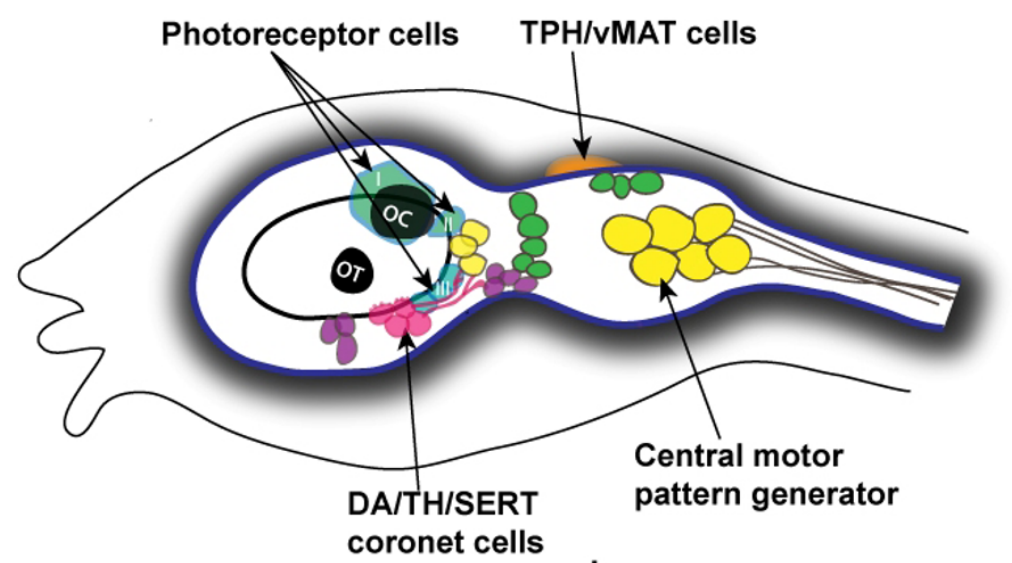

\section{\begin{tabular}{l|l} 
Sensory vesicle & Trunk ganglion \\
\hline
\end{tabular}}

Figure 1 Expression of CiPtf1a in dopamine cells of the sensory vesicle of $C$. intestinalis larva. Dorsal views of heads of $C$. intestinalis larvæ expressing CFP in TH cells (pSP-Ci-TH-CFP) (a), as well as the Kaede reporter under the control of the CiPtf1a promoter (pSP-Ci-Ptf1a Kaede) (b) in the sensory vesicle of ascidian larva; merged image (c). Ot : otolith and Oc : ocellus. (anterior to the left, scale bar, 50 m). Ot, otolith and Oc, ocellus. (scale bar, $50 \mu \mathrm{m}$ ). (c) Schematic drawing of a lateral view of the head and neck of an ascidian larva (the tail is not shown). The head CNS is shaded and divided into sensory vesicle the trunk ganglion. The neuronal populations expressing identified neurotransmitters are grossly shown. The DA coronet cells (pink), also expressing SERT and Ptf1a, are in close relationships with the population III of photoreceptors and one population of cholinergic neurons (yellow). They send processes toward glutamatergic (purple) and GABAergic (green) neurons. The TPH/vMAT expressing cells, which are localized dorso-laterally to the CNS are shown only on the right side. The central motor pattern generator and mostly the cholinergic output neurons are shown.

tryptophan hydroxylase $(\mathrm{CiTPH})$, the key enzyme of serotonin synthesis, which flanks the trunk ganglion [29], formerly named visceral ganglion [14]. Transcripts of GTP cyclohydrolase I $(\mathrm{CiGCH})$, the key enzyme in the synthesis of tetrahydrobiopterin, an essential cofactor of both $\mathrm{TH}$ and $\mathrm{TPH}$, was the only marker present at both sites (Figure 2c, d). Two genes encoding vesicular monoamine transporter (CiVMAT) and two genes encoding aromatic amino acid decarboxylase (CiAADC) were found in the Ciona genomes, as the result of a specific duplication in the ascidian lineage. One of the $v M A T$ genes is expressed specifically in the TPH peripheral domain while the other one did not show any signal (Figure 2i, j). In contrast, no signal for any of the $A A D C$ genes was detected in the $C i T P H$-expressing territory, whereas the second $A A D C$ is expressed at the same location as the $T H$ cells (Figure $2 \mathrm{e}, \mathrm{f}$ ). No sequence related to the plasma membrane DA or noradrenaline transporters (DAT and NET) exists in the Ciona genomes, probably a secondary loss in the ascidian lineage, whereas a serotonin transporter-like sequence (CiSERT) was present, as previously reported [30]. Most surprisingly, CiSERT transcript appeared to be expressed in the $T H$ but not in the TPH domains of the tail-bud embryos and larvae (Figure 2g, h). Finally, these cells displayed bulbous protrusions (coronets) into the cavity of the sensory vesicle (see Additional file 1 Figure S2 h-j), as previously described [18].

The $T H$-expressing cells were shown to contain DA [18] and, as such, they should co-express AADC, the second enzyme in the DA synthesizing pathway. Indeed, the $A A D C$ promoter drove the expression of the Kaede reporter protein in the same cells that also displayed the $\mathrm{TH}$-driven CFP fluorescence (Figure 3a-c). Those cells 


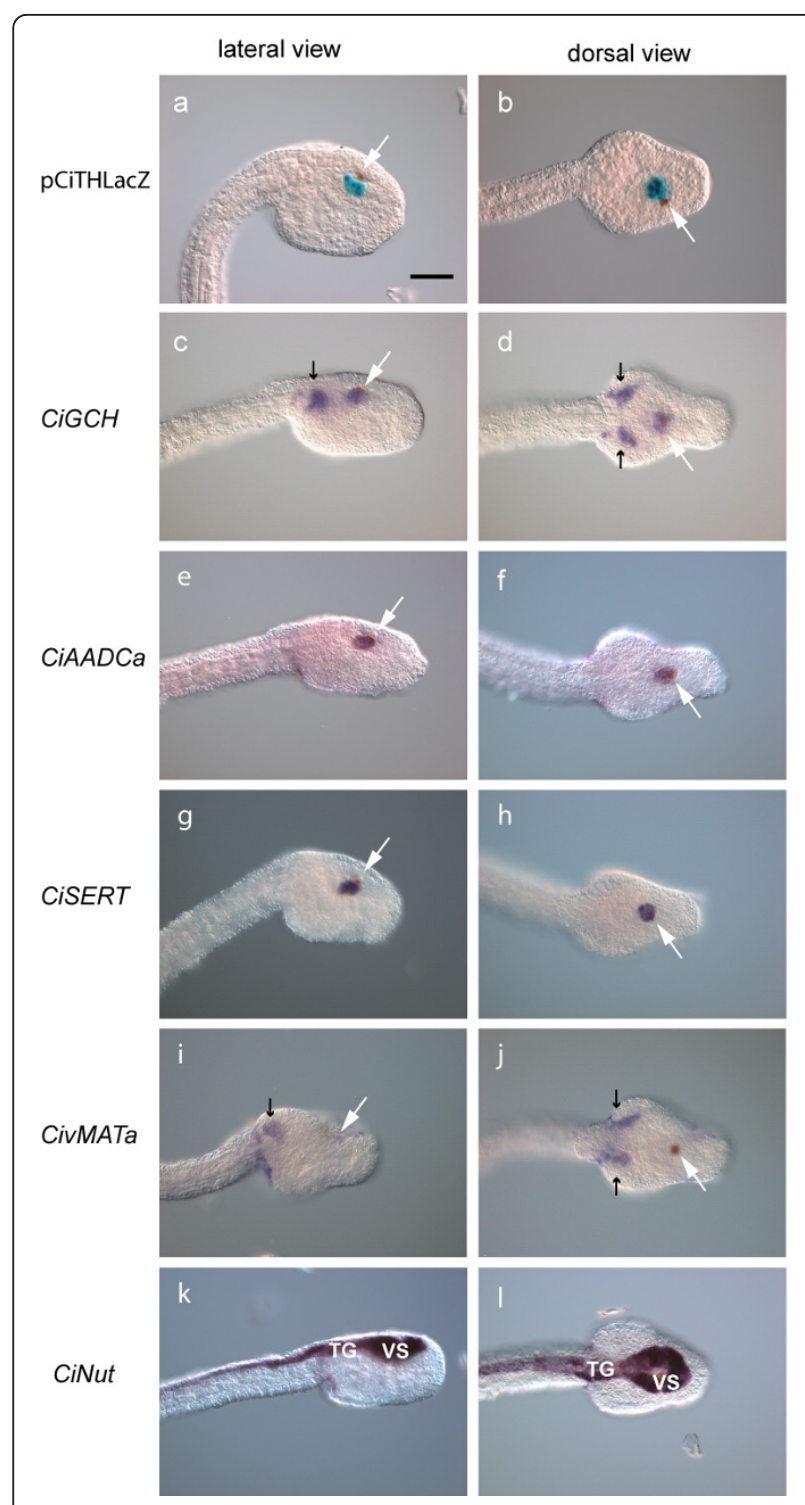

Figure 2 Expression of monoaminergic markers in $C$. intestinalis embryos. Lateral ( $\mathbf{a}, \mathbf{c}, \mathbf{e}, \mathbf{g}, \mathbf{i}, \mathbf{k}$, anterior to the right) and dorsal views (b, $\mathbf{d}, \mathbf{f}, \mathbf{h}, \mathbf{j}, \mathbf{l}$, anterior to the right) of late-tailbud-stage embryos. $(a, b) \beta$-galactosidase activity driven by the CiTH cis-regulatory sequence (pCiTH-LacZ) (dopamine cells) is detected in the ventral sensory vesicle. (c-I) In situ hybridization of the indicated probes. White arrows point to the pigmented otolith. (c, d) CiGch is expressed in two domains, one corresponding to the CITH expressing cell population within the sensory vesicle and the other to the CiTph territory flanking the trunk ganglion (small black arrows). CiAadc- $a(e, f)$ and CISERT $(g, h)$ are expressed in the CiTH domain, while CivMat- $a(i, j)$ is expressed at the same location as CiTph, outside of the nervous system (small black arrows). To accurately localize these transcripts, we used CiNut $(k, l)$ as a panneural marker expressed in the CNS including the sensory vesicle (SV) and the trunk ganglion (TG). Sense probes gave no signal (data not shown). Scale bar $=20 \mu \mathrm{m}$. also co-localize the fluorescent reporter under the control of the GCH (Figure 3d-f) and SERT promoters (Figure $3 \mathrm{~g}-\mathrm{i}$ ), and are thus characterized as DA-synthesizing cells exhibiting a SERT-like transporter.

The presence of SERT in DA cells of the sensory vesicle prompted us to look for the presence of 5-HTimmunoreactivity in the $\mathrm{TH}$-expressing cells of Ciona embryos, larvae and juveniles. No 5-HT staining was observed in embryos and larvae (see Additional file 1, Figure S1a, b), although 5-HT-positive cells were found at several locations in the juveniles (see Additional file 1 , Figure S1d-f). This is probably due to the poor sensitivity of 5-HT immunolabelling, since 5-HT could be detected by fluorometry after HPLC even at the earliest stages. The levels of 5 -HT decreased from egg $(3.5 \pm 2.9$ fmoles/individual) to larva $(1.8 \pm 1.5$ fmoles/individual $)$ before increasing again during the post-metamorphic stages (see Additional file 1, Figure S1g), suggesting that the origin of 5-HT is maternal throughout pre-metamorphic life.

Then, larvae treated with exogenous 5-HT (see Methods) were immunostained to test for 5-HT uptake capacity (as is the case in amacrine cells of the vertebrate retina [31]). In this condition, specific 5-HT immunolabelling was easily detected in the $\mathrm{CiTH}$-expressing cells of the ventral sensory vesicle (co-localization with the Venus fluorescent protein driven by the $\mathrm{CiTH}$ promoter (see Additional file 1, Figure S2a, b). 5-HT uptake was partially inhibited by a pre-treatment with Fluoxetine, a selective SERT blocker (see Additional file 1, Figure S2c). Similarly, 5-HT accumulated in a few cells of the ventral sensory vesicle of another ascidian species, Phallusia mammillata, indicating that this is not a peculiarity of C. intestinalis (see Additional file 1, Figure S2d). It is thus very likely that $5-\mathrm{HT}$ could be stored together with DA in the CiTH-expressing cells of the sensory vesicle, a property shared by some vertebrate amacrine cells [31].

\section{Investigating the role of $\mathrm{DA} / 5 \mathrm{HT}$ neurotransmission on motor control in ascidian larvae}

The possible similarities between DA-synthesizing/5HTaccumulating cells of the ascidian sensory vesicle with DA amacrine cells of the vertebrate retina prompted us to test whether these cells would be able to modulate responses to light in the ascidian larvae. This functional role was analyzed on the swimming behavior of Ciona larvae through the effect of Fluoxetine, a specific blocker of SERT. In ascidian larvae, swimming activity consists of three distinct patterns: oriented tail flicks, regular spontaneous swimming and photosensitive swimming. It 


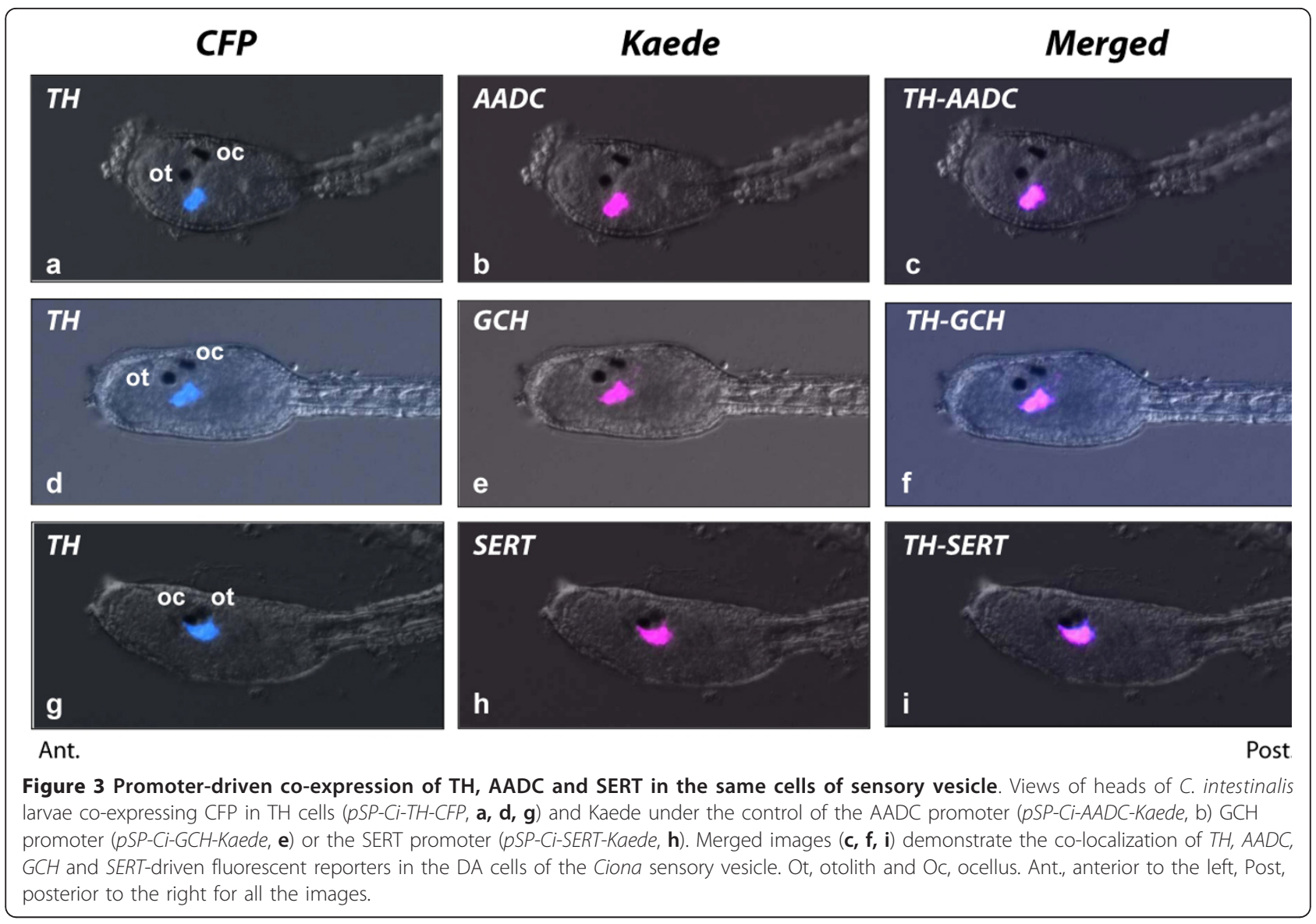

is driven by a central pattern generator [32,33], which resides in the trunk or motor ganglion and requires only tonic drive from the sensory vesicle to operate [33,34].

In control larvae, spontaneous swimming lasts for two to three hours after hatching, before the animal becomes sessile and begins metamorphosis [35]. Electrophysiological recordings from larval tail muscle showed that control larvae exhibited regular spontaneous swimming activity (see Additional file 1, Figure S3a, b). A brief step-down in light ( 1 second) induced bouts of highspeed swimming in control larvae, with an after-effect lasting for around 30 to 40 seconds (see Additional file 1, Figure S3e). The light-off activity lasted only as long as the stimulus, before the internal burst frequency gradually decreased. In the presence of $10 \mu \mathrm{M}$ Fluoxetine, the duration of this after-effect decreased with an increase in the frequency of the underlying spontaneous bursts (see Additional file 1, Figure S3e). Fluoxetine at $20 \mu \mathrm{M}$ abolished the spontaneous bursts and the aftereffects (see Additional file 1, Figure S3e) and washing failed to completely reverse the effects.

To get insight into the location of the effect of the SERT blockade within the motor network, the larvae were severed at the neck region (Figure 1d). This procedure resulted in "headless" larvae that did not swim (see Additional file 1, Figure 3f). Addition of Lglutamate to such preparations induced swimming activity very similar to the spontaneous swimming observed in intact larvae (see Additional file 1, Figure S3g), but application of $20 \mu \mathrm{M}$ Fluoxetine did not promote obvious change in either frequency or duration of the swimming bursts (see Additional file 1, Figure S3h, i). This result suggested that the effect of SERT blockade took place in the sensory vesicle to modulate both spontaneous and shadow response swimming. Taken together, these data showed that the blockage of ciSERT by Fluoxetine is able to modulate spontaneous and light-triggered motor responses, probably through the generation of an increase in extracellular DA and 5HT.

\section{Monoamines modulate photic responses via $\alpha 2$} adrenoreceptors on target neurons in Ciona

As a possible functional parallel between amacrine and ascidian DA cells, we next examined the anatomical relationships of the ascidian DA cells with other neurotransmitter systems. The expression of fluorescent reporters driven by the promoters of genes encoding vesicular transporters for glutamate (CivGLUT [36]), 
GABA (CivGAT [37]) and acetylcholine (CivACHT [37]) was compared to that of $\mathrm{CiTH}$. The corresponding constructs appeared to be expressed in neurons neighboring the CiTH-expressing cells. Specifically, DA cells made large somatic contacts with the glutamatergic, GABAergic and cholinergic neurons of the sensory vesicle (Figure $4 \mathrm{a}, \mathrm{b}$ and $4 \mathrm{c}$ respectively), suggesting that the transmitters released by the CiTH-expressing cells could modulate the activity of target cells by non-synaptic mechanisms ("volume transmission").

We looked for the presence of monoamine receptors in the sensory vesicle of $C$. intestinalis. Surprisingly, the genome of Ciona does not contain any sequence resembling the bilaterian D1- or D2-like receptor gene [38]. In contrast, we identified nine sequences potentially encoding monoaminergic-like receptors, including five 5-HT-like receptors (Ci5-HT1-a, Ci5-HT1-b, Ci5-HT2, Ci5-HT7- $a$ and Ci5-HT7-b) and four adrenergic-like receptors (ADR, two ADR $\beta$-like receptors, $C i A D R \beta-a$ and $C i A D R \beta-b$ and two ADR $\alpha 2$-like CiADR $\alpha 2-a$ and CiADR $\alpha 2-b$; see Additional file 1, Information table II). Since D1-like and D2-like receptors are present in most protostomes and deuterostomes, they are likely to have been secondarily lost in Ciona. Nonetheless, several ADR receptors were shown to respond to dopamine in vertebrates [39,40], as well as in amphioxus [41] raising the possibility that in $C$. intestinalis, the target of DA signaling are the ADR-like receptors.

To test this hypothesis, we analyzed the localization of three out of four ADR-like receptors transcripts in Ciona intestinalis larva: CiADR $\beta-a, C i A D R \beta-b$ and $C i A-$ $D R \alpha 2-a$ and. Only CiADR $\alpha 2-a$ transcripts were detected in the sensory vesicle and also in some peripheral neurons (Figure 4d-o, and data not shown). The cells expressing CiADR $\alpha 2-a$ were more precisely identified by the distribution of the fluorescent protein driven by the corresponding 5 ' upstream regulatory sequences. The expression of the reporter transgenes displayed some mosaïcism from one experiment to another, but the pattern obtained in dozens of larvae in at least five independent experiments per transgene was always very similar and consistent. The $\mathrm{pCiADR} \alpha 2-a$ driven fluorescence was localized in the CiTH expressing cells (Figure $4 \mathrm{~d}-\mathrm{f}$ ), where CiADR $\alpha 2-a$ may act as an autoreceptor. It is also found in glutamatergic neurons of the head (Figure 4g-i), including glutamatergic PRCs, in other glutamatergic neurons of the sensory vesicle and in rostral trunk epidermal neurons, as well as in GABAergic neurons of the sensory vesicle (Figure $4 \mathrm{j}-1$ ) and of the middle dorsal part of the tail (not shown). Conversely, pCiADR $\alpha 2-a$ drove no reporter expression in cholinergic neurons (Figure 4m-o) either in GABAergic neurons of the anterior nerve cord (Figure $4 \mathrm{j}-1$ ) or in the glutamatergic neurons of the tail. Many of the neurons expressing CiADR $\alpha 2-a$ are found at a distance from the $\mathrm{TH}$ cells and their processes, suggesting that DA may act through volume transmission as described in the vertebrate retina [42].

A specific agonist of the ADR $\alpha 2$ receptor (dexmedetomidine, $20 \mu \mathrm{M}$ ) produced a decrease in spontaneous activity and a decrease in the duration of the light-off response, which terminated before the end of the lightoff stimulus (Figure $5 ; n=12$ ). The effect was similar to that of fluoxetine (Figure $5 ; n=20$ ), suggesting that the neurotransmitters released from the CiTH/SERT cells may indeed act through CiADR $\alpha 2$ receptors. Atipamizole, an ADR $\alpha 2$ receptor antagonist $(20 \mu \mathrm{M})$ had an opposing effect, increasing the duration of the spontaneous swimming bursts and the duration of the light-off effect (Figure $5 ; n=15$ ). These effects were very consistent and observed in all the performed experiments. All these effects disappeared upon washing. As in the case of Fluoxetine, the "headless" preparations did not show any alterations in spontaneous swimming upon treatment with dexmedetomidine or atipamizole, suggesting again that the control exerted on the photomotor response took place upstream of the central motor generator. Thus, as shown for vertebrate amacrine cells, the monoamines released by the DA cells of the sensory vesicle could modulate light responses by the activation of ADR 2 receptors on target neurons.

\section{Discussion}

Our comprehensive examination of the molecular and functional characteristics of the DA cells of the sensory vesicle of Ciona intestinalis revealed unanticipated common features with the DA-producing amacrine cells of the vertebrate retina. Because DA cells of the sensory vesicle of $C$. intestinalis also share traits with the DA neurons of the vertebrate hypothalamus, a major implication of our work is that these types very likely derive from DA-synthesizing cells that were already present in a primitive proto-hypothalamo-retinal territory at the anterior neural tube of ancestral chordates. A second conclusion of these findings is that the multiple cell types found in the vertebrate retina and involved in photoreception, including PRCs, ganglion cells and amacrine cells, existed before the formation of the retina as an organ, as suggested from other studies conducted in Drosophila [4]. Thus, the absence of amacrine and other accessory cell types in the retina of hagfish, an animal that effectively lives in the dark, would represent a secondary loss, in agreement with the monophyly of cyclostomes [12] and with the presence of monoaminergic amacrine cells in lampreys [17].

The evidence supporting homology between vertebrate DA amacrine cells and the DA cells of the sensory vesicle of Ciona intestinalis are based both on shared 


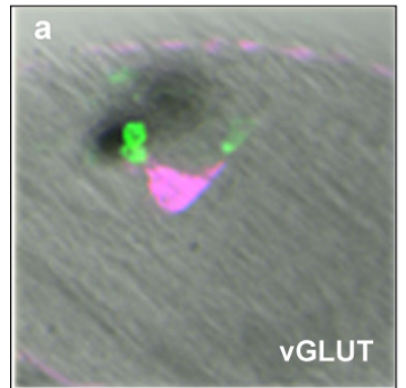

ant
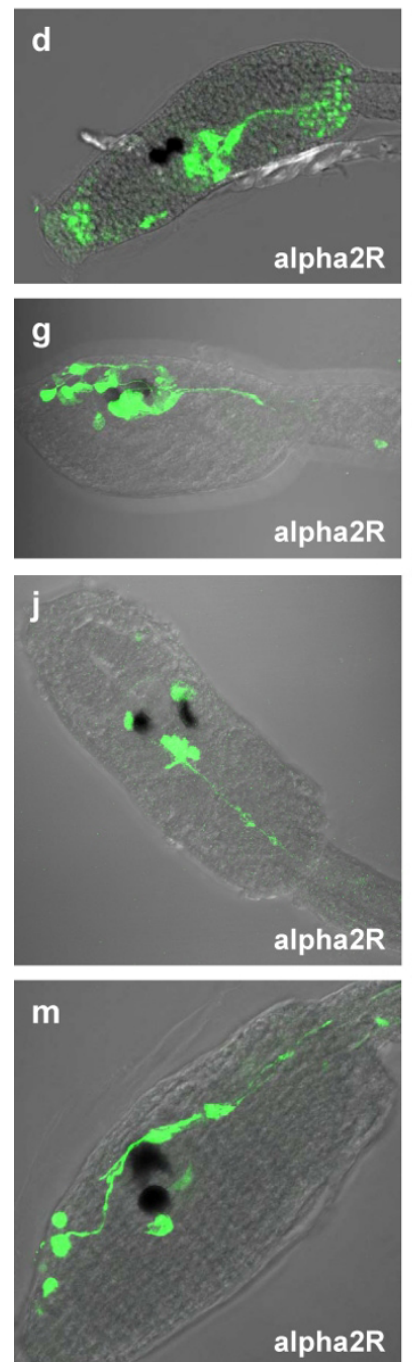
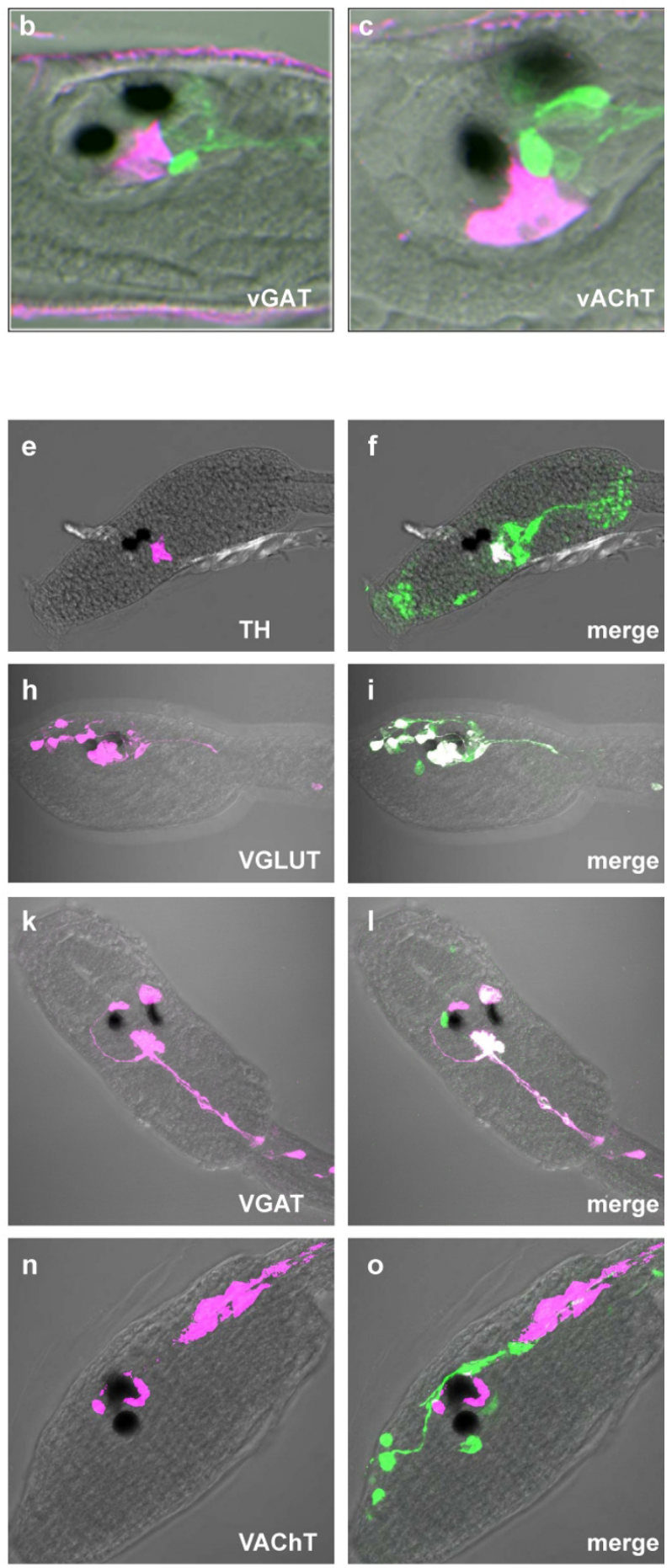

Figure 4 Expression of $C i T H$ and of $C i-A D R \alpha 2 a$ receptor in the neuronal network of $C$. intestinalis larva. Confocal sections of larvae COelectroporated with $p C i$-TH-WGA and constructs reporting expression of the following neurotransmitter markers: $(\boldsymbol{a}, \boldsymbol{d})$ glutamate transporter (pCi-vGluT-eGFP), $(\boldsymbol{b}, \boldsymbol{e})$ GABA transporter ( $p C i$-VGaT-eGFP) and $(\boldsymbol{c}, \boldsymbol{f})$ acetylcholine transporter (pCi-VAchT-eGFP). Localizations of WGA (red) and eGFP (green) were visualized by immunofluorescent staining with an anti-WGA antibody and an anti-GFP antibody, respectively. Merged images $(a, b, c)$ corresponds to merged images with Nomarski channel $(d, e, f)$. A, anterior, P, posterior. (Scale bar, $25 \mu \mathrm{m}$ in $(a, b), 10 \mu \mathrm{m}$ in c.). (c-n) Confocal sections of larvae with co-electroporated $p C i-A D R \alpha 2 a-V e n u s$ and constructs reporting expression of the following markers of neurotransmitter systems: (c, d, e) dopamine (pCiTH-Kaede), (f, g, h) glutamate (pCi-vGluT-Kaede), (i, j, k) GABA (pCi-vGaT-Kaede) and (l, m, n) acetylcholine ( $p$ Ci-VAchT-Kaede). Localization of Venus (green) $(c, f, i, l)$ Kaede (red) $(d, g, j, m)$ were respectively visualized by immunofluorescent staining with an anti-Kaede antibody and an anti-GFP antibody. $(d, h, k, n)$ merged images of anti-Kaede and anti-Venus staining. These are representative example of all the performed experiments ( $n=5$ to 15$)$ depending on the couple of transgenes used. 


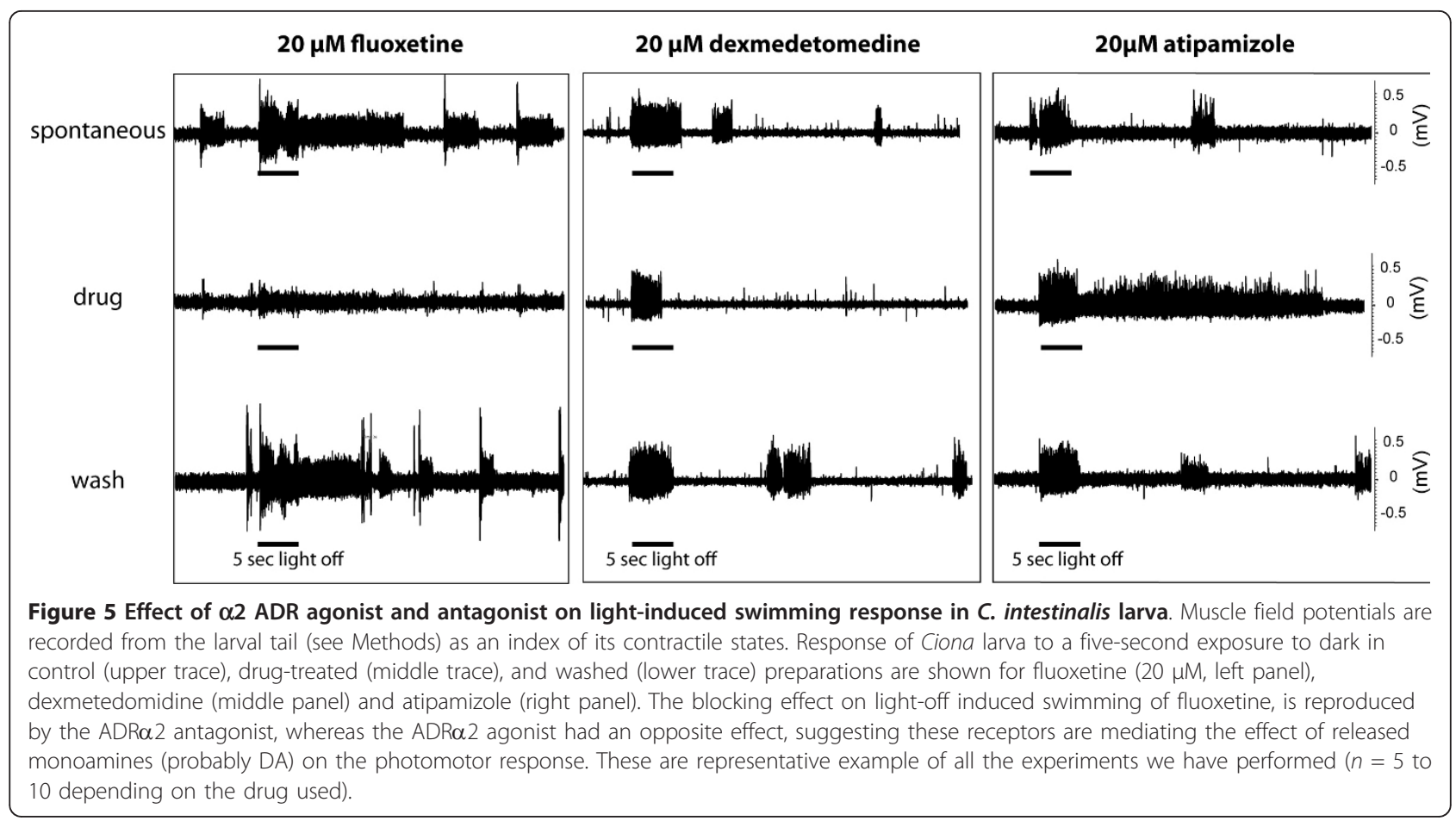

neurochemical and molecular signatures and on functional characteristics. Beside the fact they express the whole set of molecules required to synthesize, store and release DA (TH, AADC and VMAT), the DA cells in Ciona display the unusual ability to take up and store serotonin (5HT). Serotonin-accumulating amacrine cells have been described in several vertebrate species $[17,31,43]$ and, similarly, DA cells of the $C$. intestinalis larva are able to take up 5-HT via the SERT present in these cells. We postulate that this CiSERT should be able to transport DA in addition to $5 \mathrm{HT}$, since no DAT (absent from the genome) is present in DA cells of the sensory vesicle, although this is an unusual property for SERT $[30,44]$. Supporting this contention, the blockage of CiSERT by Fluoxetine, a widely used SERT inhibitor, has a robust inhibitory effect on the swimming activity induced by shadowing, in Ciona larvae. This inhibitory effect is probably mediated by the action of DA on ADR $\alpha 2-$ like receptors, since no DA receptors are present in the Ciona genome [38]. The action of DA through ADR $\alpha 2$-a receptors has also been described in the vertebrate hypothalamus $[39,40]$. The affinity of ADR $\alpha 2$-like receptors for dopamine is only about 10fold lower than that of noradrenaline in most vertebrates $[39,40]$, allowing them to be contingently used as DA receptors in some tissues and some species.

In vertebrates, DA amacrine cells modulate light responses of the retinal network through lateral inhibition $[1,2]$ and the ascidian DA cells modulate the swimming behavior elicited by PRC activation. In the two cases, this effect in mediated, at least in part, by ADR $\alpha 2-$ like receptors. In C. intestinalis, ADR $\alpha 2$-like receptors are located on DA cells, as in vertebrate amacrine cells where they act as autoreceptors [45], and also on glutamatergic photoreceptors and GABAergic interneurons, the probable targets of secreted DA. A reminiscent situation is found in vertebrates where the three paralogous $\mathrm{ADR} \alpha 2 \mathrm{~A} / \mathrm{B} / \mathrm{C}$ receptor subtypes are expressed in PRCs (glutamatergic), RGCs (glutamatergic) and amacrine cells (mostly GABAergic), with some species differences [46]. A role of this DA-induced inhibition in ascidian larvae could be to promote the onset of metamorphosis, which is associated with the immobilization of the larvae and attachment to a substrate. In contrast, it was shown that blocking 5-HT receptors delayed the onset in P. mammillata larvae [35]. It is thus very likely that $5 \mathrm{HT}$ and DA have opposing effects on motor behavior in ascidians, this effect depending on the integrity of the connection between the sensory vesicle and the motor pattern generator in the trunk (see Additional file 1 Figure S3).

Incidentally, our data also highlight the large molecular flexibility and evolutionary adaptability of these DA and $5 \mathrm{HT}$ systems, with the loss in ascidian genomes of monoamine transporter genes except SERT [30], the loss of D1-like and D2-like receptors encoding genes [38]. Yet the systems remain functional by using SERT and ADR $\alpha 2$-like receptors for DA uptake and effect on target cells. 
The similarity between DA cells of the ascidian sensory vesicle and DA amacrine cells of the vertebrate retina is reinforced by the shared expression of Ptf1a, bHLH transcription factor [25,26]. Ptf1a is mandatory for the formation of horizontal and amacrine cells, especially GABAergic amacrine cells [23]. The DA cells of Ciona do not contain GABA in addition to DA as in vertebrates [43], but Ptfla can be expressed in all types of amacrine cells in vertebrates [26], and GABA and DA cells can be separate cell types. Other transcription factors, such as CiRx, CiSix3/6, CiPax6 and CiMeis, which contribute to retina development $[20,21,47]$, are also localized in the anterior medial and lateral part of the sensory vesicle, where DA cells are located in Ciona $[18,19,47,48]$. Overall, these observations clearly show that DA cells are present in a photoreceptive territory in the ascidian sensory vesicle, as the amacrine cells are in the vertebrate retina.

In addition to their similarity to amacrine cells, the DA cells of the sensory vesicle of $C$. intestinalis also share traits with the CSF-contacting dopamine neurons of the vertebrate hypothalamus [18]. In Ciona, the ventral location of the DA cells and their protrusions (coronets) in the lumen of the sensory vesicle make them resemble the DA coronet cells of the saccus vasculosus of cartilaginous and teleost fishes, a paraventricular organ of the hypothalamus, secondarily lost in tetrapods, as well as to the dopamine-synthesizing cells of the caudal hypothalamus in teleosts [reviewed in [49]].

Based on commonalities with the hypothalamus of vertebrates, we previously hypothesized that the area of the ascidian sensory vesicle where DA cells are located was homologous as a field to the hypothalamus of the vertebrate brain [19]. Based on our present results, it seems now more likely that the sensory vesicle of ascidians on the one hand, and, on the other hand, the hypothalamus and retina together, ancestrally derive from a photoreceptive neuroepithelium folded into the anterior neural tube of ancestral chordates, as initially proposed by F.K. Studnicka in 1898, based on embryological data and a remarkable intuition [reviewed in [50]].

This hypothesis fits with the observation that deep brain photoreceptors and photoreceptive organs (retina and epiphysis) are all derived from the ventricle-lining prosencephalon [51,52]. In this respect, the ascidian PRCs would be equally related to the PRCs of the retina, the epiphysis and the hypothalamus of vertebrates. Furthermore, in the amphioxus Branchiostoma floridae, a non-craniate chordate which lacks a true retina, some cilliary PRCs express Pax6 [50], and these cells are part of the cerebrospinal fluid (CSF)-contacting neurons sitting in the wall of the cerebral vesicle [51,52], a region proposed to be homologous to the vertebrate prosencephalon [52,53]. In addition, DA cells of the anterior cerebral vesicle of the amphioxus are located close to these photoreceptors $[54,55]$, a situation somewhat reminiscent of that of Ciona.

\section{Conclusion}

Based on our data and compilation of many previous studies, the following hypothesis can be put forward: The dopamine cells of the ascidian larvae derive from an ancestral multifunctional cell population located in the periventricular, photoreceptive field of the anterior neural tube of chordates, which also give rise to both anterior hypothalamus and retina in craniates/vertebrates. In vertebrates, hypothalamus and retina derive from adjacent territories of the neuroepithelium of the presumptive ventral secondary prosencephalon. Whether the hypothalamic and retinal fields are clearly separated from the origin needs to be further investigated. Then, the future retina bulges out of the secondary prosencephalon simultaneously with a movement of subduction of the hypothalamus [56]. Both retina and hypothalamus kept the potency to make photoreceptors and neurosecretory cell types, such as DA amacrine cells or DA neuronal types in the hypothalamic nuclei $[52,57,58]$. As a corollary, vertebrates have evolved towards subfunctionalized monoaminergic systems in the retina and hypothalamus, whereas ascidians have retained a multifunctional monoaminergic cell population (Figure 6). Involvement of DA cells of ascidian larvae in both sensory and motor modulation may represent a vestigial ancestral state. Finally, these findings also implicate that the existence of multiple cell types associated with photic responses predates the formation of the vertebrate retina.

\section{Materials and Methods}

\section{Animals and embryos}

Ciona intestinalis adults were collected in three different places: in France, from the Station de Biologie Marine de Roscoff; in Italy, from the Marine Animals Resources Service of the Stazione Zoologica A. Dohrn in the bay of Naples; in Japan, in Aioi Bay or in Murotsu Port. It is thus not possible to rule out that the animal could belong to two subspecies. However, the genes of the various proteins used in this study, the sequences of which were analyzed in the different locations were strikingly similar, and the animal morphologies also were highly similar, and this does not affect the observations and conclusion reached in this study. The animals were maintained in artificial sea water at 15 to $18^{\circ} \mathrm{C}$ under constant light to avoid spawning. Eggs and sperm were collected separately from dissected gonads and used in cross-fertilizations. For embryological studies, fertilized eggs were dechorionated according to [19] and raised at 13 to $18^{\circ} \mathrm{C}$ on $2 \%$ agarose-coated dishes in 


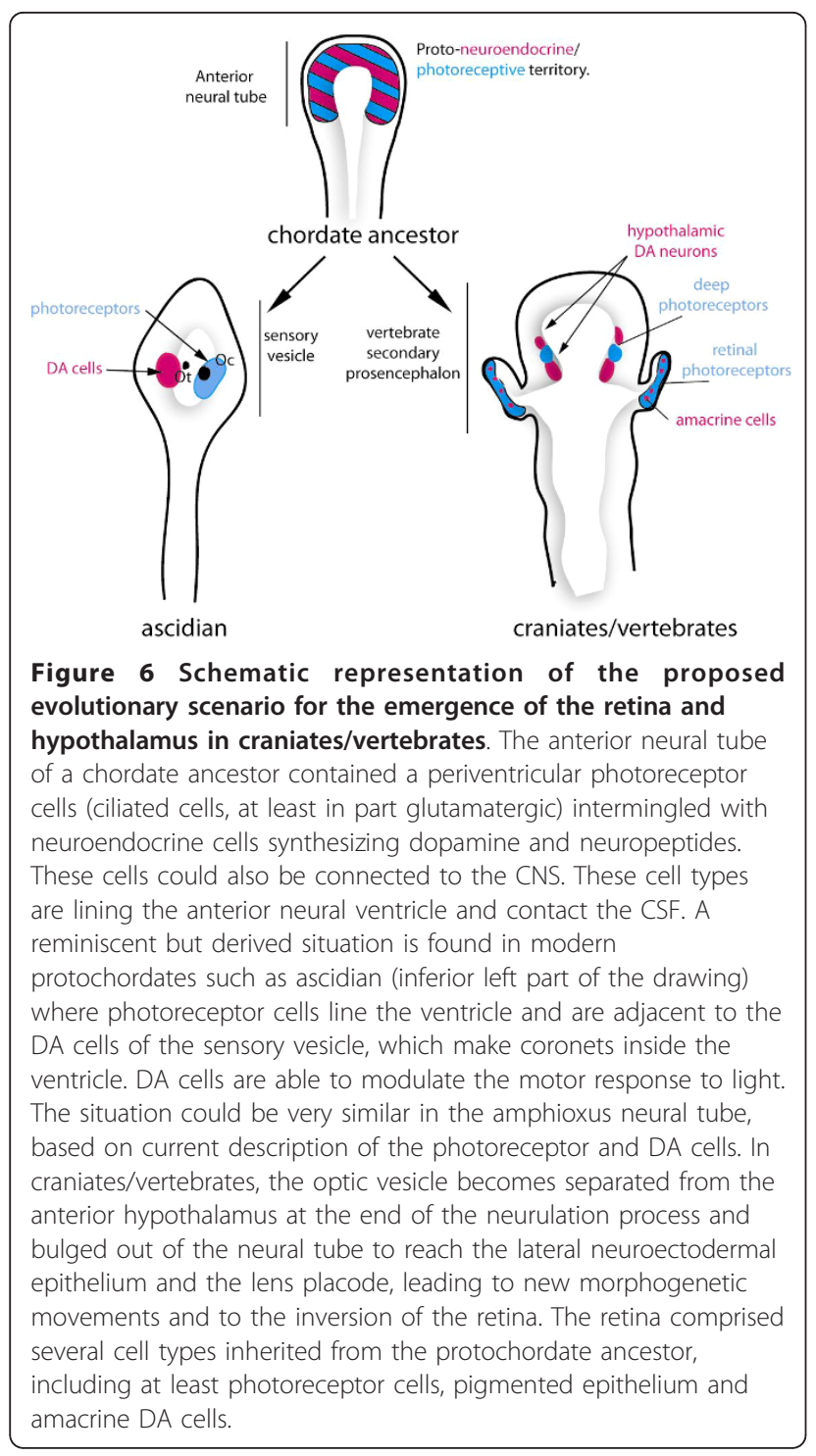

filtered artificial sea water buffered with Hepes (ASWH; under these conditions larvae hatch at around 19.5 to $20.5 \mathrm{hr}$ ). For post metamorphic stages, animals were transferred on non-coated dishes in ASWH and raised to the desired stage without food in order to keep them translucent. For immunohistochemistry and in situ hybridization, animals were fixed in PFA $4 \%$ in ASWH and $0.1 \%$ Tween, overnight or more at $4{ }^{\circ} \mathrm{C}$. After fixation, samples were progressively dehydrated in Ethanol series EtOH 25\% PBS 0.1\% Tween (PBSTw), EtOH 50\% - PBST, EtOH 80\%-H2O and eventually stored in $\mathrm{MEOH}$ at $-20^{\circ} \mathrm{C}$ for several months.

\section{Isolation of Ciona intestinalis genes}

Total RNA from larvae and late-tail-bud embryos of Ciona intestinalis were extracted with a Nucleospin extract II kit (Macherey-Nagel, Düren, Germany)). For reverse transcription, around $2 \mu \mathrm{g}$ RNA of each developmental stage was annealed with oligo dT and hexamer random primers, followed by cDNA synthesis using M-MLV point mutant-reverse transcriptase, according to the manufacturer's protocol (Promega, Madison, Wisconsin, USA). A total of 50 to $100 \mathrm{ng}$ of the resulting cDNAs were used as templates for the polymerase chain reaction (PCR), using GoTaq DNA polymerase (Promega). Specific primers used for each PCR are listed in Additional file 1, Table III. The PCR products were cloned in pCRII plasmids using TOPO TA Cloning (Invitrogen, Carlsbad, California, USA) for synthesizing the cRNA probe for in situ hybridization. The plasmids were subsequently sequenced and orthology of novel genes was checked by molecular phylogeny. Partial sequences of all the predicted genes were obtained (see Additional file 1, Table I). A longer fragment of $\mathrm{CiTph}$ was provided by [25] and CiPtf1a was retrieved from the EST library Ciona Gene Collection release 1 (clone ID cilv050i16).

\section{Serotonin detection and whole mount anti-serotonin immunohistochemistry}

Serotonin (5-HT) was assayed as follows: Ciona intestinalis embryos, larvae and juveniles of the appropriate stages were counted and transferred in tubes with ASWH. They were then centrifuged at $4^{\circ} \mathrm{C}$ for five minutes. Supernatant was carefully removed and replaced with $400 \mu \mathrm{L}$ a solution of a $10^{-3} \mathrm{M}$ chlorohydric acid solution and kept on ice before sonication, with consecutive short pulses. Then, samples were stored at $-80^{\circ} \mathrm{C}$ before $5-\mathrm{HT}$ was assayed by HPLC and fluorometric detection as previously described [59].

To test for 5-HT uptake larvae were incubated with 5-HT (Serotonin creatinine sulfate complex H7752, Sigma-Aldrich, St. Louis, Missouri, USA) (50 or $100 \mu \mathrm{M})$ diluted in ASWH for one hour. The uptake of 5-HT was inhibited by pre-treating larvae with Fluoxetine $(50 \mu \mathrm{M})$ diluted in ASWH for 30 minutes before incubation with 5-HT $(50 \mu \mathrm{M})$ in presence of Fluoxetine $(50 \mu \mathrm{M})$ for one hour. Thereafter, larvae were quickly rinsed in ASWH and fixed in PFA $4 \%$ in ASWH - $0.1 \%$ Tween, overnight at $4{ }^{\circ} \mathrm{C}$.

Then, samples were processed for whole mount anti-5HT immunohistochemistry essentially as described in [60]. Samples were rehydrated progressively in PBSTw and next in PBTR (PBS, Triton 0.5\%, DMSO 1\%), incubated one hour at RT in PBTR-NGS $1 \%$ and then incubated with a rat monoclonal anti-5-HT antibody (MAB352, Chemicon, Billerica, Massachusetts, USA) in PBTR-NGS $1 \%$ at $4{ }^{\circ} \mathrm{C}$ overnight to 48 hours. Samples were then rinsed in PBTR and incubated again in PBTR-NGS 1\% for one hour at room temperature and overnight incubated with the secondary antibody (biotinylated monoclonal goat anti rat antibody, Jackson ImmunoResearch Laboratories, West Grove, Pennsylvania, USA) in PBTR-NGS $1 \%$ at $4^{\circ} \mathrm{C}$. After 
rinsing with PBSTw, the antigen-antibodies complexes were detected using the ABC peroxydase Kit (Vector Laboratories Inc., Burlingame, California, USA). Peroxydase activity was detected by using either diaminobenzidine (DAB, DiamAB Sigma) or Alexafluor568 tyramide (TSA kit, Molecular Probes, Eugene, Oregon, USA), according to the supplier's instructions. Samples were then mounted under coverslip in 50\% glycerol-PBST for DAB revelation, or Vectashield with DAPI (Vector Laboratories Inc.) for fluorophore conjugated tyramides. DABstained specimens were observed with a Leica DMR Microscope (Leica Microsystems, Nanterre, Franceand photographed with a Nikon Digital camera DXM 1200 (Nikon, Shinjuku, Tokyo, Japan).

\section{Reporter gene constructs and electroporations}

Different plasmid constructs were used in this study. $p$ CiTH-LacZ, $p C i$-vGluT-eGFP, $p$ CivGAT-eGFP and $p C i$ $V A c h T-e G F P$ are respectively the same as in $[18,36,37]$. The $p C i T H$-WGA, pCiTH-Kaede, pCi-vGluT-Kaede, pCivGAT-Kaede and pCi-VachT-Kaede were made inserting the $5^{\prime}$ upstream corresponding sequences in front of reporter genes, either Kaede or Wheat germ agglutinin (WGA) as described in [36,37]. To generate pSP-CiTH-Kaede, pSP-CiTH-CFP, pSP-CiPtf1a-CFP, pSP-CiAADC-Kaede, pSP-CiGCH-Kaede, pSP-CiSERTKaede, the 5' upstream regions of $\mathrm{Ci}$-TH, Ci-Ptf1a, Ci$A A D C, C i-G C H$ and $C i-S E R T$, were amplified by PCR using a thermostable DNA polymerase (PrimeSTAR HS DNA polymerase, Takara Bio Inc., Otsu, Shiga, Japan) and oligonucleotide primers (5'-tggatcccggtcacgggtgcctacctc-3' and 5'-gggatccatttttaaattacgtttttt-3' for $\mathrm{Ci}-\mathrm{TH}$, 5'-gtggatccgtatgcgtggtgtgtatgaacg-3' and 5' - ggggatccatgttatactacgttgataact-3' for Ci-Ptf1a, 5'-acggatccaatgacgtaataatcaactt-3' and 5'-ggggatccatttttgcagcggattctt-3' for $\mathrm{Ci}$ $A A D C, 5^{\prime}$-agggatccggcactagattggtgtac-3' and 5' - ggggatccatattttagacctgttaatt-3' for $\mathrm{Ci}-\mathrm{GCH}, 5^{\prime}$-ggggatcctagtttaccacgaagagtt-3' and 5'- ggggatccatattggtgattttttcaata-3' for Ci-SERT). The PCR products were digested with $\mathrm{BamHI}$ and were inserted in the BamHI site of pSPKaede and pSPeCFP. $p$ CiADR $\alpha 2-a$-Venus was made using a Gateway cloning system (Invitrogen) as in [61] after amplification of the 5'upstream region of CiADR $\alpha 2$ with Gateway specific primers (5'-attB1-CTCGAGtggtatttcagagaactacagtttcaa-3' and 5'-attB2-CTCTAGActtccatggttaaataatcatcataca-3'). The reporter proteins were immunostained with the appropriate primary and secondary antibodies as described in [36].

\section{In situ hybridization and $\beta$-galactosidase detection}

In situ hybridization of whole-mount specimens was carried out as described in [19]. Electroporations and Xgal staining were performed essentially as previously described in [61].

\section{Physiological recordings of motor behavior and modulation by monoaminergic drugs}

All the drugs and compounds were purchased from Sigma unless otherwise specified. The drugs were diluted from concentrated stock solutions and added to the superfusate at the final concentrations indicated.

To test for the effects of drugs on the swimming behavior of Ciona larvae, video recordings of larval movements were made at five-minute intervals from individual larvae in filtered seawater with a high speed video (Fast-Cam Rabbit mini 2, Photoron Tokyo, Japan) at 400 to $500 \mathrm{fps}$ mounted on a binocular microscope and stored for later analysis. In some cases, the 'head' was transected between the motor ganglion and brain vesicle $(\mathrm{BV})$, disconnecting it from the motor ganglion and tail.

For electrophysiological recordings, larvae were placed either in Petri dishes containing a base of 1\% agar or, in dishes coated with $1 \%$ bovine serum albumin. Both approaches prevented the larvae contacting the plastic base of the Petri dish and commencing metamorphosis. All experiments were carried out in filtered sea-water perfused over the preparation at a $8 \mathrm{ml} / \mathrm{minute}$ rate. Glass micropipettes were drawn from borosilicate glass of $1.5 \mathrm{~mm}$ OD on a microelectrode puller (Model P87, Sutter Instrument Co., Novato, California, USA). The tips of the electrodes were broken under microscopic control so that their internal diameter was about fourfifths the diameter of the larval tail. Coarse manipulation of the microscope stage allowed the larval tail to be brought into close contact with the tip of the electrode and negative pressure was applied to draw the larval tail into the pipette to about two-thirds of its length. Muscle action potentials were recorded differentially between the inside of the pipette and the sea-water of the bath and amplified (DAM 80, World Precision Instruments, New Haven, CT, USA) with reference to a silver chloride pellet placed in the bath. Signals were AC-coupled and passed between $0.1 \mathrm{~Hz}$ and $10 \mathrm{kHz}$, digitized and stored by the Digidata 1200 data acquisition system (Molecular Devices, Sunnyvale, CA, USA)) until being analyzed with Clampfit software 9.0 (Molecular Devices, Sunnyvale, CA, USA). A custom-built shutter was controlled by $5-\mathrm{V}$ pulses delivered from the Digidata board allowing a step-down in the light intensity for a given time.

\section{Additional material}

Additional file 1: Data supporting the contention of the article: Monoaminergic modulation of photoreception in ascidian: Evidence for a proto-hypothalamo-retinal territory. Two tables of the genes studied in the paper, the first one with the references of the genes encoding components of the monoamine neurotransmission pathway, the second one with the reference of the genes encoding monoamine 
receptors and found in the Ciona genome. One figure demonstrating the presence of serotonin in the ascidian larvae (Figure 1). One figure showing the uptake of serotonin in the dopamine cells of the ascidian sensory vesicle (Figure 2). One figure showing that dopamine and serotonin can modulate the light-induced swimming behaviour of the larva of Ciona intestinalis (Figure 3).

\section{Abbreviations}

5-HT: serotonin; ADR: adrenergic receptor; ASWH: artificial sea water with Hepes; DA: dopamine; PRCs: photoreceptor cells; SERT: serotonin transporter; TH: tyrosine hydroxylase; Tph: tryptophane hydroxylase; VMAT: vesicular monoamine transporter.

\section{Acknowledgements}

This work was supported by grants from CNRS, the University Paris-Sud, the Fondation de France and Agence Nationale pour la Recherche -contract DANET (to PV). This work is also supported in part by grants from JSPS (to TGK). FRK was supported by the Ministry of Research and the Fondation pour la Recherche Médicale. We thank Yasuko Terashima for her technical assistance and Gabriele Ferrandino for technical assistance in the electrophysiological experiments.

\section{Author details}

${ }^{1}$ Neurobiology and Development, UPR3294, Institut de Neurobiologie Alfred Fessard, Centre National de la Recherche Scientifique, Gif-sur-Yvette, 91190, France. ${ }^{2}$ Department of Animal Physiology and Evolution, Stazione Zoologica Anton Dohrn, Naples, 80121, Italy. ${ }^{3}$ Shimoda Marine Research Center, University of Tsukuba, 5-10-1 Shimoda, Shizuoka 415-0025, Japan. ${ }^{4}$ Laboratoire de biochimie, Hôpital Lariboisière, Paris, 75010, France. ${ }^{5}$ Department of Biology, Faculty of Science and Engineering, Konan University, Kobe 658-8501, Japan. ${ }^{6} J a p a n$ Science and Technology Agency, PREST, 4-1-8 Honcho, Kawaguchi, Saitama 332-0012, Japan. ${ }^{7}$ New York University Center for Developmental Genetics, Department of Biology, New York University, 1009 Silver Center, 100 Washington Square East, New York, NY 10003-6688, USA. ${ }^{8}$ Institute of Biological Chemistry, Biophysics and Bioengineering, School of Engineering and Physical Sciences, Heriot-Watt University, Edinburgh EH14 4AS, UK.

\section{Authors' contributions}

FRK conceived the study, carried out all the cloning, molecular biology experiments, phylogenetic analysis, participated in electrophysiological experiments and drafted the manuscript. EB conceived and carried out the electrophysiological and pharmacological experiments with FRK and contributed to writing the manuscript. TH made several of the transgenic constructs used to study the target of dopamine neurons in ascidian sensory vesicle, and to perform co-localization studies, supervised by YS. JC carried out the monoamine assays and interpreted the data. JSJ contributed to design and supervision of the work, and to writing the paper. TGK participated in the design of the study and contributed in analyzing most of the data. PV conceived the study, and participated in its design and coordination and wrote the manuscript. All authors read and approved the final manuscript.

\section{Authors' information}

FRK did his PhD work in PV's team under the supervision of PV and JSJ. He is currently a post-doctoral fellow at the Department of Biology at New York University, New York, USA.

EB was group leader and head of the Department of Animal Physiology and Evolution at the Stazione Zoologica Anton Dohrn, Villa Comunale, in Naples, Italy. He is now group leader in the Institute of Biological Chemistry at Heriot-Watt University, Edinburgh, EH14 4AS, UK.

TH did his PhD under TK's supervision at Hyogo University, Japan. He is now assistant professor at the Shimoda Marine Research Center, University of Tsukuba, Japan.

YS is Associate Professor and group leader at the Shimoda Marine Research Center, University of Tsukuba, Japan. He is a world-renown specialist of the developmental biology of ascidia.
$J C$ is full professor at the Department of Biochemistry and Molecular Biology, Hopital Lariboisière, Paris, France. His work is dedicated to the study of monoamines in human pathologies.

JSJ is group leader at the Neurobiology and Development Research Unit, CNRS, Institute of Neurobiology Alfred Fessard, Gif-sur-Yvette, France. He is a well-known specialist of the development of protochordate, especially ascidia.

TGK is professor at the Department of Biology, Konan University, Kobe, Japan and a well-known specialist of the biology of ascidia and photoreceptor systems, as well as bioinformatics.

PV is the head of the Neurobiology and Development Research Unit, CNRS and director of the Institute of Neurobiology Alfred Fessard, Gif-sur-Yvette,

France, and a specialist of the evolution of nervous system in chordates.

\section{Competing interests}

The authors declare that they have no competing interests.

Received: 10 April 2012 Accepted: 29 May 2012 Published: 29 May 2012

\section{References}

1. Masland RH: Neuronal diversity in the retina. Curr Opin Neurobiol 2001, 11:431-436.

2. Lamb TD, Collin SP, Pugh ENJ: Evolution of the vertebrate eye: opsins, photoreceptors, retina and eye cup. Nat Rev Neurosci 2007, 8:960-976.

3. Arendt $D$, Hausen $H$, Purschke G: The 'division of labour' model of eye evolution. Philos Trans R Soc Lond B Biol Sci 2009, 364:2809-2817.

4. Erclik T, Hartenstein V, Mclnnes RR, Lipshitz HD: Eye evolution at high resolution: the neuron as a unit of homology. Dev Biol 2009, 332:70-79.

5. Arendt $D$ : The evolution of cell types in animals: emerging principles from molecular studies. Nat Rev Genet 2008, 9:868-882.

6. Janvier P: Early jawless vertebrates and cyclostome origins. Zoolog SCi 2008, 25:1045-1056.

7. Ota KG, Fujimoto S, Oisi Y, Kuratani S: Identification of vertebra-like elements and their possible differentiation from sclerotomes in the hagfish. Nat Commun 2011, 2:373.

8. Holmberg K: The hagfish retina: fine structure of retinal cells in Myxine glutinosa, L., with special reference to receptor and epithelial cells. $Z$ Zellforsch Mikrosk Anat 1970, 111:519-538.

9. Collin SP: Evolution and ecology of retinal photoreception in early vertebrates. Brain Behav Evol 2010, 75:174-185.

10. Takezaki N, Figueroa F, Zaleska-Rutczynska Z, Klein J: Molecular phylogeny of early vertebrates: monophyly of the agnathans as revealed by sequences of 35 genes. Mol Biol Evol 2003, 20:287-292.

11. Villar-Cervino V, Abalo XM, Villar-Cheda B, Melendez-Ferro M, Perez-Costas E, Holstein GR, Martinelli GP, Rodicio MC, Anadon R: Presence of glutamate, glycine, and gamma-aminobutyric acid in the retina of the larval sea lamprey: comparative immunohistochemical study of classical neurotransmitters in larval and postmetamorphic retinas. $J$ Comp Neurol 2006, 499:810-827.

12. Bourlat SJ, Juliusdottir T, Lowe CJ, Freeman R, Aronowicz J, Kirschner M, Lander ES, Thorndyke M, Nakano H, Kohn AB, Heyland A, Moroz LL, Copley RR, Telford MJ: Deuterostome phylogeny reveals monophyletic chordates and the new phylum Xenoturbellida. Nature 2006, 444:85-88.

13. Delsuc F, Brinkmann H, Chourrout D, Philippe H: Tunicates and not cephalochordates are the closest living relatives of vertebrates. Nature 2006, 439:965-968.

14. Dufour HD, Chettouh Z, Deyts C, de Rosa R, Goridis C, Joly JS, Brunet JF: Precraniate origin of cranial motoneurons. Proc Natl Acad Sci USA 2006, 103:8727-8732.

15. Ikuta T, Saiga H: Dynamic change in the expression of developmental genes in the ascidian central nervous system: revisit to the tripartite model and the origin of the midbrain-hindbrain boundary region. Dev Biol 2007, 312:631-643.

16. Horie T, Sakurai D, Ohtsuki H, Terakita A, Shichida Y, Usukura J, Kusakabe T, Tsuda M: Pigmented and nonpigmented ocelli in the brain vesicle of the ascidian larva. J Comp Neurol 2008, 509:88-102.

17. Abalo XM, Villar-Cervino V, Villar-Cheda B, Anadon R, Rodicio MC: Neurochemical differentiation of horizontal and amacrine cells during transformation of the sea lamprey retina. J Chem Neuroanat 2008, 35:225-232. 
18. Moret F, Christiaen L, Deyts C, Blin M, Joly JS, Vernier P: The dopaminesynthesizing cells in the swimming larva of the tunicate Ciona intestinalis are located only in the hypothalamus-related domain of the sensory vesicle. Eur J Neurosci 2005, 21:3043-3055.

19. Moret F, Christiaen L, Deyts C, Blin M, Vernier P, Joly JS: Regulatory gene expressions in the ascidian ventral sensory vesicle: evolutionary relationships with the vertebrate hypothalamus. Dev Biol 2005, 277:567-579

20. Jean D, Bernier G, Gruss P: Six6 (Optx2) is a novel murine Six3-related homeobox gene that demarcates the presumptive pituitary/ hypothalamic axis and the ventral optic stalk. Mech Dev 1999, 84:31-40.

21. Heine P, Dohle E, Bumsted-O'Brien K, Engelkamp D, Schulte D: Evidence for an evolutionary conserved role of homothorax/Meis1/2 during vertebrate retina development. Development 2008, 135:805-811.

22. Oliver G, Mailhos A, Wehr R, Copeland NG, Jenkins NA, Gruss P: Six3, a murine homologue of the sine oculis gene, demarcates the most anterior border of the developing neural plate and is expressed during eye development. Development 1995, 121:4045-4055.

23. Satou Y, Kawashima T, Shoguchi E, Nakayama A, Satoh N: An integrated database of the ascidian, Ciona intestinalis: towards functional genomics. Zoolog Sci 2005, 22:837-843.

24. Tassy O, Dauga D, Daian F, Sobral D, Robin F, Khoueiry P, Salgado D, Fox V, Caillol D, Schiappa R, Laporte B, Rios A, Luxardi G, Kusakabe T, Joly JS, Darras S, Christiaen L, Contensin M, Auger H, Lamy C, Hudson C, Rothbächer U, Gilchrist MJ, Makabe KW, Hotta K, Fujiwara S, Satoh N, Satou Y, Lemaire P: The ANISEED database: digital representation, formalization, and elucidation of a chordate developmental program. Genome Res 2010, 20:1459-1468.

25. Fujitani Y, Fujitani S, Luo H, Qiu F, Burlison J, Long Q, Kawaguchi Y, Edlund H, MacDonald RJ, Furukawa T, Fujikado T, Magnuson MA, Xiang M, Wright CV: Ptf1a is expressed transiently in all types of amacrine cells in the embryonic zebrafish retina. Development 2006, 84:31-40.

26. Jusuf PR, Harris WA: Ptf1a is expressed transiently in all types of amacrine cells in the embryonic zebrafish retina. Neural Dev 2009, 4:34.

27. Dehal P, Satou Y, Campbell RK, Chapman J, Degnan B, De Tomaso A, Davidson B, Di Gregorio A, Gelpke M, Goodstein DM, Harafuji N, Hastings KE, Ho I, Hotta K, Huang W, Kawashima T, Lemaire P, Martinez D, Meinertzhagen IA, Necula S, Nonaka M, Putnam N, Rash S, Saiga H, Satake M, Terry A, Yamada L, Wang HG, Awazu S, Azumi K, et al: The draft genome of Ciona intestinalis: insights into chordate and vertebrate origins. Science 2002, 298:2157-2167.

28. Small KS, Brudno M, Hill MM, Sidow A: A haplome alignment and reference sequence of the highly polymorphic Ciona savignyi genome. Genome Biol 2007, 8:R41.

29. Pennati R, Candiani S, Biggiogero M, Zega G, Groppelli S, Oliveri D, Parodi M, De Bernardi F, Pestarino M: Developmental expression of tryptophan hydroxylase gene in Ciona intestinalis. Dev Genes Evol 2007, 217:307-313.

30. Caveney S, Cladman W, Verellen L, Donly C: Ancestry of neuronal monoamine transporters in the Metazoa. J Exp Biol 2006, 209:4858-4868.

31. Fletcher EL, Wassle $\mathrm{H}$ : Indoleamine-accumulating amacrine cells are presynaptic to rod bipolar cells through $\mathrm{GABA}(\mathrm{C})$ receptors. J Comp Neurol 1999, 413:155-167.

32. Horie T, Nakagawa M, Sasakura Y, Kusakabe TG, Tsuda M: Simple motor system of the ascidian larva: neuronal complex comprising putative cholinergic and GABAergic/glycinergic neurons. Zoolog Sci 2010, 27:181-190.

33. Nishino A, Okamura Y, Piscopo S, Brown ER: A glycine receptor is involved in the organization of swimming movements in an invertebrate chordate. BMC Neurosci 2010, 11:6.

34. Brown ER, Nishino A, Bone Q, Meinertzhagen IA, Okamura Y: GABAergic synaptic transmission modulates swimming in the ascidian larva. Eur J Neurosci 2005, 22:2541-2548.

35. Zega G, Pennati R, Groppelli S, Sotgia C, De Bernardi F: Dopamine and serotonin modulate the onset of metamorphosis in the ascidian Phallusia mammillata. Dev Biol 2005, 282:246-256.

36. Horie T, Kusakabe T, Tsuda M: Glutamatergic networks in the Ciona intestinalis larva. J Comp Neurol 2008, 508:249-263.

37. Yoshida R, Sakurai D, Horie T, Kawakami I, Tsuda M, Kusakabe T: Identification of neuron-specific promoters in Ciona intestinalis. Genesis 2004, 39:130-140.
38. Kamesh N, Aradhyam GK, Manoj N: The repertoire of G protein-coupled receptors in the sea squirt Ciona intestinalis. BMC Evol Biol 2008, 8:129.

39. Ruffolo RRJ, Goldberg MR, Morgan EL: Interactions of epinephrine, norepinephrine, dopamine and their corresponding alpha-methylsubstituted derivatives with alpha and beta adrenoceptors in the pithed rat. J Pharmacol Exp Ther 1984, 230:595-600.

40. Cornil CA, Ball GF: Interplay among catecholamine systems: dopamine binds to alpha2-adrenergic receptors in birds and mammals. J Comp Neurol 2008, 511:610-627.

41. Burman C, Reale V, Srivastava DP, Evans PD: Identification and characterization of a novel amphioxus dopamine D1-like receptor. J Neurochem 2009, 111:26-36.

42. Contini M, Raviola E: GABAergic synapses made by a retinal dopaminergic neuron. Proc Natl Acad Sci USA 2003, 100:1358-1363.

43. Huang S, Moody SA: Dual expression of GABA or serotonin and dopamine in Xenopus amacrine cells is transient and may be regulated by laminar cues. Vis Neurosci 1998, 15:969-977.

44. Torres GE, Gainetdinov RR, Caron MG: Plasma membrane monoamine transporters: structure, regulation and function. Nat Rev Neurosci 2003, 4:13-25.

45. Hadjiconstantinou M, Cohen J, Rubenstein JS, Neff NH: An endogenous ligand modulates dopamine-containing neurons of retina via alpha-2 adrenoceptors. J Pharmacol Exp Ther 1984, 229:381-385.

46. Woldemussie E, Wijono M, Pow D: Localization of alpha 2 receptors in ocular tissues. Vis Neurosci 2007, 24:745-756.

47. D'Aniello S, D'Aniello E, Locascio A, Memoli A, Corrado M, Russo MT, Aniello F, Fucci L, Brown ER, Branno M: The ascidian homolog of the vertebrate homeobox gene $\mathrm{Rx}$ is essential for ocellus development and function. Differentiation 2006, 74:222-234.

48. Irvine $\mathrm{SQ}$, Fonseca VC, Zompa MA, Antony R: Cis-regulatory organization of the Pax6 gene in the ascidian Ciona intestinalis. Dev Biol 2008, 317:649-659.

49. Joly JS, Osorio J, Alunni A, Auger H, Kano S, Retaux S: Windows of the brain: towards a developmental biology of circumventricular and other neurohemal organs. Semin Cell Dev Biol 2007, 18:512-524.

50. Walls GL: The Vertebrate Eye and its Adaptive Radiation New York: Hafner; 1942.

51. Satir P: A comment on the origin of the vertebrate eye. Anat Rec 2000, 261:224-227.

52. Vigh B, Manzano MJ, Zadori A, Frank CL, Lukats A, Rohlich P, Szel A, David C: Nonvisual photoreceptors of the deep brain, pineal organs and retina. Histol Histopathol 2002, 17:555-590.

53. Lacalli TC: Sensory systems in amphioxus: a window on the ancestral chordate condition. Brain Behav Evol 2004, 64:148-162.

54. Kozmik Z, Holland ND, Kreslova J, Oliveri D, Schubert M, Jonasova K Holland LZ, Pestarino M, Benes V, Candiani S: Pax-Six-Eya-Dach network during amphioxus development: conservation in vitro but context specificity in vivo. Dev Biol 2007, 306:143-159.

55. Moret F, Guilland JC, Coudouel S, Rochette L, Vernier P: Distribution of tyrosine hydroxylase, dopamine, and serotonin in the central nervous system of amphioxus (Branchiostoma lanceolatum): implications for the evolution of catecholamine systems in vertebrates. J Comp Neurol 2004, 468:135-150.

56. England SJ, Blanchard GB, Mahadevan L, Adams RJ: A dynamic fate map of the forebrain shows how vertebrate eyes form and explains two causes of cyclopia. Development 2006, 133:4613-4617.

57. Vigh-Teichmann I, Vigh B: The system of cerebrospinal fluid-contacting neurons. Arch Histol Jpn 1983, 46:427-468.

58. Byerly MS, Blackshaw S: Vertebrate retina and hypothalamus development. Wiley Interdiscip Rev Syst Biol Med 2009, 1:380-389.

59. Kema IP, Schellings AM, Hoppenbrouwers CJ, Rutgers HM, de Vries EG Muskiet FA: High performance liquid chromatographic profiling of tryptophan and related indoles in body fluids and tissues of carcinoid patients. Clin Chim Acta 1993, 221:143-158.

60. Teraoka H, Russell C, Regan J, Chandrasekhar A, Concha ML, Yokoyama R, Higashi K, Take-Uchi M, Dong W, Hiraga T, Holder N, Wilson SW: Hedgehog and Fgf signaling pathways regulate the development of tphRexpressing serotonergic raphe neurons in zebrafish embryos. I Neurobiol 2004, 60:275-288.

61. Roure A, Rothbacher U, Robin F, Kalmar E, Ferone G, Lamy C, Missero C, Mueller F, Lemaire P: A multicassette Gateway vector set for high 
throughput and comparative analyses in Ciona and vertebrate embryos. PLoS One 2007, 2:e916.

doi:10.1186/1741-7007-10-45

Cite this article as: Razy-Krajka et al:: Monoaminergic modulation of

photoreception in ascidian: evidence for a proto-hypothalamo-retinal territory. BMC Biology 2012 10:45

Submit your next manuscript to BioMed Central and take full advantage of:

- Convenient online submission

- Thorough peer review

- No space constraints or color figure charges

- Immediate publication on acceptance

- Inclusion in PubMed, CAS, Scopus and Google Scholar

- Research which is freely available for redistribution

Submit your manuscript at 